\title{
Evaluation of the use of birth control followed in women's hospital regional Saint Louis (Senegal) in 2014
}

\author{
Ousmane Thiam ${ }^{1 *}$, Mamadou Lamine Cissé2 ${ }^{2}$ Mansour Ninag ${ }^{3}$, Mamour Gueye ${ }^{3}$, \\ Abdou Aziz Diouf ${ }^{3}$, Cherif Cheikh Tourade SARR ${ }^{4}$, Aly Sambou ${ }^{1}$, Jean Charles Moreau ${ }^{3}$
}

\author{
${ }^{1}$ Health Training Unit (UFR2S), Gaston Berger University of Saint Louis, Senegal \\ ${ }^{2}$ UFR Health, University of Thies, Senegal \\ ${ }^{3}$ Gynecological and Obstetrical clinic, CHU, Aristide le Dantec, University Cheikhe Anta. Diop of Dakar, Senegal \\ ${ }^{4}$ Hospital Regional Center of Saint Louis, Senegal
}

Received: 27 February 2017

Accepted: 31 March 2017

\section{*Correspondence:}

Dr. Ousmane Thiam,

E-mail: cassoumane@yahoo.fr

Copyright: (c) the author(s), publisher and licensee Medip Academy. This is an open-access article distributed under the terms of the Creative Commons Attribution Non-Commercial License, which permits unrestricted non-commercial use, distribution, and reproduction in any medium, provided the original work is properly cited.

\begin{abstract}
Background: To evaluate the use of contraceptive methods among women followed at Saint Louis Health Centre. Methods: This was a descriptive cross-sectional study of all recue clients in the Obstetrics and Gynecology department of the Regional Hospital of St. Louis. She ran from 1 January 2014 to 31 December 2014, 12 months.

Results: The mean age was 28.8 years. The most common demographic characteristics were the Wolof ethnic group $(64.5 \%)$, married the marital status (97.9\%), they were not in school in $46.3 \%$. The main sources of information on the use of contraception were health workers in $80.3 \%$, friends and relatives $(8.5 \%)$ followed by husbands $(2.5 \%)$, the media represented $60 \%$ and $0.1 \%$ posters. The injection method was the most used method $(42.8 \%)$ followed by implants $(36.2 \%)$, pills $(14.9 \%)$ and tubal ligation (4.4\%). The IUD was the least used method with $1.7 \%$ of use. The main reasons given by women were spacing births $(70.6 \%)$, to avoid unwanted pregnancy $(3.90 \%)$, avoid early pregnancies $(1.20 \%)$ and of other unspecified reasons in $24.3 \%$. In this study, no accidental pregnancy was reported. Indeed, $79.4 \%$ of women had respected the monitoring schedule of monitoring visits. They had abandoned contraception in $23.5 \%$.

Conclusions: This study shows the achievements and shortcomings in relation to the nature and completeness of the information provided. Strengthening the awareness and training will reduce missed opportunities for family planning, and indirect; reduce the rate of unmet need for FP in our country.
\end{abstract}

Keywords: Family planning, Long way

\section{INTRODUCTION}

In sub-Saharan Africa, one woman in twelve dies during pregnancy or childbirth against a four thousand in the developed countries. ${ }^{1}$ In Senegal, the direct estimate of the maternal mortality rate from DHS V for the period $1998-2005$ is 401 maternal deaths per 100,000 live births. $^{2}$ This rate has seen a remarkable decrease compared to that estimated by the DHS II 1992-1993 where he was 510 per 100,000 live births for the period 1986-1992. ${ }^{3}$ Women aspire to be better educated, better informed and have more control of their own lives and fertility. ${ }^{4}$

Demographic problems have never experienced such acute face dwindling resources caused by the economic crisis and the level of population growth; which actually increase hunger and child mortality in underdeveloped countries. $^{4}$ 
This study is part of a research on the monitoring records of women using contraception. Its purpose is to contribute to the improvement of reproductive health.

The general objective of this study was to evaluate the use of contraceptive methods among women followed at Saint Louis Health Centre. The specific objectives were to:

- Describe the sociodemographic characteristics of women followed for contraception at the St. Louis health center;

- Describe their clinical characteristics;

- Describe their contraceptive practices;

- Determine the effectiveness of contraceptive methods chosen by women;

- Clarify the determinants of contraceptive practices.

\section{METHODS}

We conducted a descriptive cross-sectional study from January to December 2014, 12 months. We conducted a comprehensive census of all client records who received a contraceptive maternity Regional Hospital in St. Louis. We included in the study all clients who have benefited:

- A concealing,

- A birth in the service.

We had not included all client monitoring in service and whose birth was performed in another service. Étudées variables were socio-demographic characteristics (age, place of origin, education level, occupation, marital status, gravidity, parity), the antecedents of the client (number of abortions, the number of death, number the living child, number of caesarean), data on contraception (information sources, method chosen, regularity of visits, drop desire, side effects). We have worked on the records of contraception and the issue of client containing all the variables. For each quantitative variable, the average is surrounded by its standard deviation. For categorical variables, we calculated the percentages as well as the $95 \%$.

\section{RESULTS}

\section{General data}

Age

The mean age was 28.84 years with a standard deviation of 25 . The youngest of the women was 14 years old and the oldest was 56 years old. Almost half (49.7\%) were aged between 25 and 35 years.

\section{Parity, Gestité}

The average gravidity was 3.3 at the extremes of 1 and 18. Women pauci gestures were the most represented with 453 women, or $51.7 \%$.
The mean parity was 2.3 with a 1.9 std. The median was 2 extremes of 0 and 11 . pauci pares women were the most represented with $55 \%$ of clients. Number of children per woman alive

The average number of living children per woman was 1.93 2,3avec an STD. The median was two extreme 0 to 11 (Figure 1).

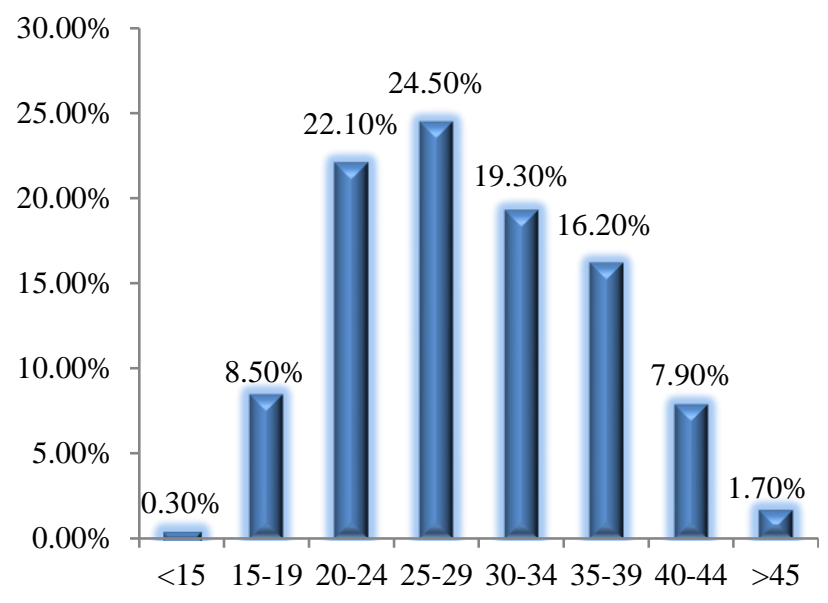

Figure 1: Distribution of women by age.

The average weight was $63.4 \mathrm{~kg}$ with a standard deviation of 13.3. The median was 61 at the extremes of 32 and $115 \mathrm{~kg}$. The average height was $158 \mathrm{~cm}$ with a standard deviation of 13.9. The median was 160 at the extremes of $100 \mathrm{~cm}$ and $185 \mathrm{~cm}$.

The majority of women were married $97.9 \%$. They were divorced $0.1 \%$. The majority of women had a husband who works on their behalf is $62.8 \%$.

The majority of women $(58.5 \%)$ consumed coffee. It noted that only $0.4 \%$ were smokers. The main sources of information for the use of contraception were $80.3 \%$ health workers.

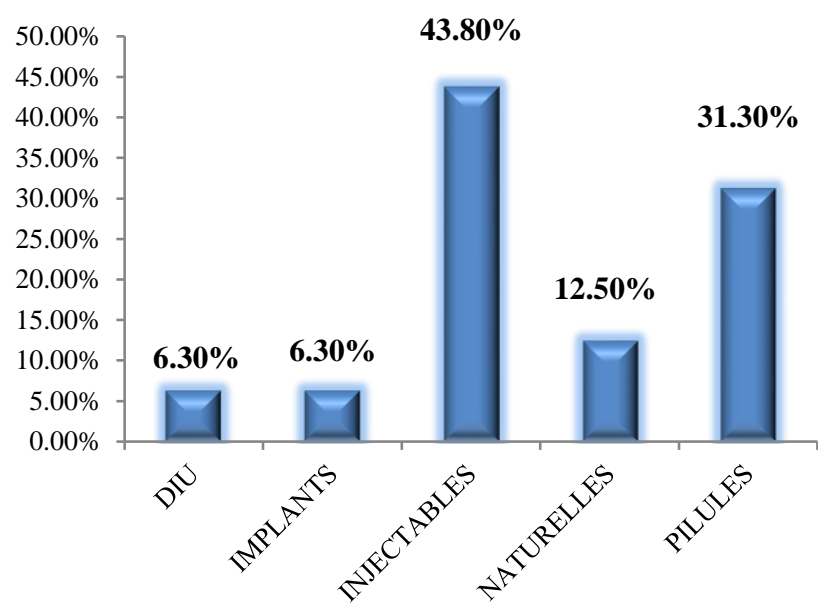

Figure 2: Distribution of Women's earlier use of contraception. 


\section{Contraceptive data}

Previous methods

Among the 428 women with contraceptive history, the majority (43.8\%) were injection method (Figure 2).

\section{Method chosen}

The injection method was the most used method (42.8\%) followed by implants $(36.2 \%)$. The IUD represented $1.7 \%$ of all methods (Figure 3 ).

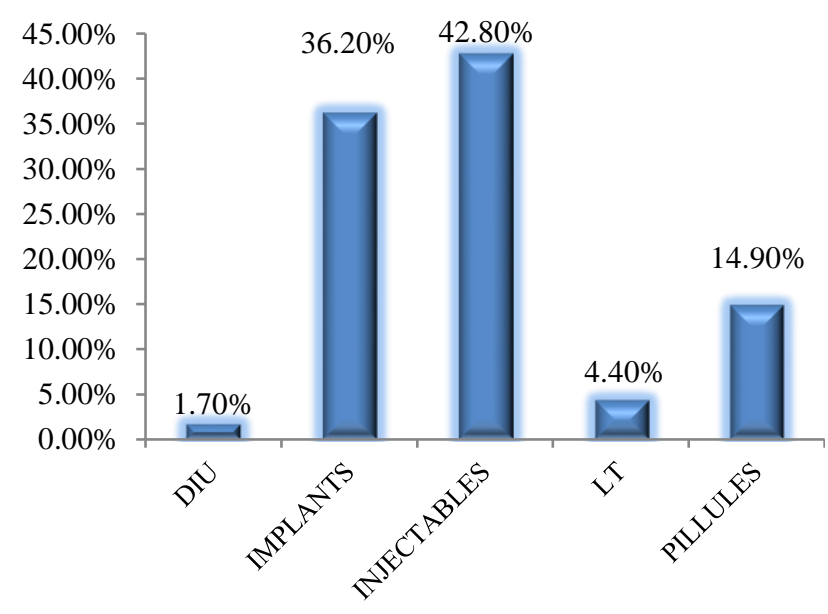

Figure 3: Distribution of women according to the current choice.

\section{Family planning reason}

The main reasons given by women were spacing births $(70.6 \%)$ and to avoid an unwanted pregnancy $(3.9 \%)$, avoid early pregnancies $(1.2 \%)$ and of other unspecified reasons in $24.3 \%$.

\section{Regularity monitoring visits}

Monitoring visits were regularly attended by 849 women, or $79.4 \%$ of users (Table 1 ).

Table 1: Distribution of women regularity of visits.

\begin{tabular}{|lll|}
\hline Regular monitoring visites & No. & Percentage \\
\hline Yes & 849 & 79,4 \\
\hline No & 220 & 20,6 \\
\hline Total & $\mathbf{1 0 6 9}$ & $\mathbf{1 0 0}$ \\
\hline
\end{tabular}

\section{Side effect}

A side effect was found in $42.15 \%$ of contraceptive users. The frequency of side effects was $42.56 \%$ in users of hormonal method and $40.0 \%$ among non-hormonal method users. In users of hormonal methods, the most common side effects were weight gain and abnormal bleeding that while in women using nonhormonal methods the most side effects were found pelvic infections and abdominal and pelvic pain.

\section{Drop desire}

During the study, two women have desires abandon contraception. In all of the patients who followed their contraceptive methods correctly no pregnancies have occurred during the period of planning.

\section{DISCUSSION}

\section{Demographics}

The average age of 28.8 years was found in our study confirming the trend of young Senegalese female population, as evidenced by the results of the EDS IV which was an average of 29.2 years. ${ }^{5}$ The age group 25 to 35 years was the most representative with $49.7 \%, 8.3 \%$ of patients were under 20 years and $6.3 \%$ were over 40 years. In the study of At Niang, $70 \%$ of patients were aged between 26 and 35 years, a percentage of $4.1 \%$ were under 20 and $12 \%$ of patients were 40 years or older. ${ }^{6}$ Several studies have shown that these two layers are the most affected by maternal, perinatal and children made from it. ${ }^{7}$ Thus, in 2010-2011, only $2 \%$ of all 15 to 19 years and $6 \%$ of the 20 to 24 report using a modern method. The proportions among married women in the same age group are slightly higher $(5 \%$ and $8 \%$, respectively). ${ }^{8}$ Access to reproductive health services remains problematic for young women and men due to cultural barriers, medical and financial, that is why they are a particular target for advice on family planning.

Our population was predominantly urban with $47.5 \%$ living in the city center against $33.1 \%$ in rural areas.

Married women were $97.9 \%$, against $2 \%$ of unmarried and divorced women were $0.1 \%$.

Non-hormonal methods are better appreciated because of their better tolerance, itself linked to the minimal side effects. Thus, women with history of contraceptives were twice as likely $(\mathrm{p}=0.001)$ to choose a nonhormonal method that new users. However, the choice of hormonal methods remains predominant in the population. Indeed, in our study, the injection method was the most used method (42.8\%) followed by implants (36.2\%), pills $(14.9 \%)$ and tubal ligation $(4.4 \%)$. The IUD was the least used method with $1.7 \%$ of use. These results are very similar to those found by Faye et al found in a survey conducted in the suburbs of Dakar that among married women, the highest proportion used the injectable contraceptive $(43 \%)$, followed by the pill $(33 \%)$ and condoms (15\%), according to a consistent trend in all age groups. However, the largest proportion of young sexually active unmarried women use condoms (56\%), followed by injection $(21 \%)$ and the pill $(14 \%) .{ }^{9}$ This reflects the level of information for users. ${ }^{10}$ In the subregion, while the use of modern FP methods in Mali is 
already low $(5.7 \%)$, it is clear from several studies that users of PF choose short-term methods such as DepoProvera or the pill. ${ }^{11}$ It is important to remember that the many works carried out on adherence it has always been concluded that the practical effectiveness of a method depends on its proper use and its observance, which are closely related to the level of membership of users, including the adaptation of this method to their lifestyle. ${ }^{5}$ The best contraception is not necessarily the most effective, but that the woman chooses.

In our study, the main reasons given by women were spacing births $(70.6 \%)$. Faye and her colleagues found that $19 \%$ of married women have an unmet need for contraception, for the purpose of spacing births in almost all cases. ${ }^{8}$ Contraception remains an effective means of birth spacing, with varying success rates depending on the type of contraception used. In this study, no accidental pregnancy was reported, indicating that contraceptive methods are effective and well followed. This is consistent with the data in the literature that reported very low pregnancy rates below $1 \%$ including hormonal contraceptive methods. ${ }^{7,12}$

\section{Determinants of contraceptive practices}

The appointment followed were met in $79.4 \%$. During these appointments, A side effect was found in $42.15 \%$ of contraceptive users. The frequency of side effects was $42.56 \%$ in users of hormonal method and $40.0 \%$ among non-hormonal method users. In users of hormonal methods, the most common side effects were weight gain and abnormal bleeding (spotting) while in women using nonhormonal methods the most found side effects were pelvic infections and abdominal and pelvic pain.

The abandonment of contraception was noted in $23.5 \%$ of the clients. The frequency of drop was $26.16 \%$ in users of hormonal method and $11.51 \%$ of non-hormonal method users. This rate was $26.2 \%$ in users of hormonal methods, and $11.6 \%$ in women using nonhormonal methods in the study of Mboup and Ly meanwhile, was the dropout rate of about $24.5 \%$ among pill users, $18.7 \%$ in women using IUDs and condoms and $5.7 \%$ among users of injectable. ${ }^{13}$ In users of hormonal methods reason to abandon the most representative were the desire for pregnancy, weight gain and "spotting" as found in the most non-hormonal contraceptive users were pelvic infections abnormal bleeding and pain abdominopelvic.

Several factors contribute to the unmet need for family planning in developing countries such ignorance of contraception; the low quality of services or lack of access; cost methods; the concern of women about side effects; and women's objections, husbands or family members in contraceptive use. A descriptive analysis of data from the Senegalese Initiative for Urban Health, women's beliefs and misconceptions about contraception, husband's objections to his practice and the low quality of family planning services are the reasons that discourage mostly urban environments Senegalese women to use contraception. ${ }^{8}$

\section{CONCLUSION}

This study shows the achievements and shortcomings in relation to the nature and completeness of the information provided. Strengthening the awareness and training will reduce missed opportunities for family planning, and indirect, reduce the rate of unmet need for FP in our country.

\section{Funding: No funding sources}

Conflict of interest: None declared

Ethical approval: The study was approved by the Institutional Ethics Committee

\section{REFERENCES}

1. Fund of the. United Nations Population. Final evaluation of the community-based reproductive health services (CBS / RH) project in the Tambacounda and Kolda regions. Dakar: UNFPA; 2008.

2. Fedblum P. Barrier methods offer dual protection. The choice of a contraceptive. Network. 1995;10(1):26-27.

3. Akem E. Contraceptive factors in Cameroon. Analysis of data from the Demographic and Health Survey 1998. 2005;47(6).

4. Morin-Ganet, Procreation. Reproductive function in humans. 2006; 6 (6): 7.

5. National Agency of Statistics and Demography. Demographic and Health Survey in Senegal (DHS) 1998-2005: EDS-IV.Direction of Statistics and Forecasting / Division of Surveys and Demography. Dakar: ANSD; 2006.

6. World Health Organization: Prevention and elimination of disrespect and ill-treatment in childbirth in health care settings, human reproductive program; 2015;4.

7. Drinking M. Evaluation of the quality of care in certain medical, medico-technical and pharmaceutical services of the Gabriel TOURE Hospital. Thesis Med. University of Bamako. 2000;69.

8. Young women 's access to and use of contraception: the role of the restrictions imposed by providers in urban areas in Senegal, International Perspectives on Sexual and Reproductive Health, special issue of; 2015:20-8.

9. Faye S. Contraception in women aged 35 and over (about 199 cases at the Gynecological and Obstetrical Clinic of the CHU A. LE Dantec in Dakar). Thesis Med., Cheikh Anta Diop University, Dakar. 2000;76:42822.

10. Sedgh G. Women with an unmet need for contraception in developing countries and their reasons for not using a method, Occasional Report, New York: Guttmacher Institute. 2007:37. 
11. Moulin M, Coquerel A. Pharmacology: Knowledge and Practice. Belgium: Masson; May 2002.740-7.

12. World Health Organization: Prevention and elimination of disrespect and ill-treatment in childbirth in health care settings, human reproductive program. 2015;4.

13. Ly P. Teenage contraception in Dakar: Multicenter study of 246 cases. Thesis on Medicine, University of Dakar, 2001;5.
Cite this article as: Thiam $O$, Cissé ML, Ninag M, Gueye M, Diouf AA, Tourade SARR CC, et al.

Evaluation of the use of birth control followed in women's hospital regional Saint Louis (Senegal) in 2014. Int J Reprod Contracept Obstet Gynecol 2017;6:1721-5. 